\title{
Natural Killer Cells Expanded and Preactivated Exhibit Enhanced Antitumor Activity against Different Tumor Cells in Vitro
}

\author{
Biplob Kumar Biswas ${ }^{1}$, Sameer Ahmad Guru², Mamta Pervin Sumi ${ }^{3}$, Elvia \\ Jamatia ${ }^{1}$, Rohit Kumar Gupta ${ }^{1}$, Pramod Lali ${ }^{1}$, Bidhan Chandra Konar ${ }^{1}$, \\ Alpana Saxena ${ }^{1 *}$, Rashid Mir ${ }^{4}$
}

\begin{abstract}
One of the emerging treatment strategies for cancer particularly for haematological malignancies is natural killer (NK) cell therapy. However, the availability of a best approach to maximize NK cell anticancer potential is still awaited. It is well established that cytokine-induced memory-like NK cells have the potential to differentiate after a short period of preactivation with interleukins-IL-12, IL-15, and IL-18 and exhibit increased responses to cytokine or activating receptor restimulation for weeks to months after preactivation. We demonstrated that NK cells differentiated from $\mathrm{CD} 34+$ cells isolated from cord blood show increased antitumor potential in vitro against different cancer cells. Using flow cytometry, we found that NK cells were able to induce apoptosis in cancer cells in vitro. We further analysed surviving gene expression by quantitative real time PCR and reported that NK cells cause down regulation of survivin gene expression in tumor cells. Therefore, NK cell therapy represents a promising immunotherapy for cancers like AML and other haematological malignancies. It concluded that NK cells can be differentiated from CD34+ cells isolated from cord blood, are able to induce apoptosis and induce increased antitumor potential in vitro against different cancer cells besides cause downregulation of survivin gene expression in tumor cells. Therefore, NK cell therapy represents a promising immunotherapy for different cancer types and haematological malignancies. Furthers studies are necessary to confirm our findings.
\end{abstract}

Keywords: Natural killer (NK)- CD34+ cells- K562 (Chronic Myeloid Leukaemia)- T47D, Umbilical Cord Blood (UCB)

Asian Pac J Cancer Prev, 21 (6), 1595-1605

\section{Introduction}

Natural killer (NK) cells are large granular lymphocytes playing role in our defense against certain virus-infected and malignant cells. Natural killer (NK) cells also lyse target cells via antibody-dependent cellular cytotoxicity, a critical mode of action of several therapeutic antibodies used to treat cancer (Rezvani and Rouce, 2015). Natural killer (NK) cells play a critical role in innate immune responses against infected cells and transformed cells (Paul and Lal, 2017) .Many researches highlight on the role of NK cells in hematologic malignancies, particularly in acute leukaemia.NK cells are capable of producing cytokines such as interferon- $\gamma($ IFN- $\gamma)$ and tumour necrosis factor- $\alpha$ (TNF- $\alpha$ ) in response to stimuli (Kronstad et al., 2018; Cerwenka and Lanier, 2016). NK cells are considered a part of lymphocytes that account for approximately $10 \%$ of blood lymphocytes. NK cells are characterized by expression of CD56 surface antigen and a lack of CD3 antigen. Based on the density of CD56 expression, human NK cells are phenotypically divided into two groups: CD56bright and CD56dim. Of these NK cell populations, CD56dim NK cells comprise up to $90 \%$ of NK cells in human peripheral blood mononuclear cells (PBMCs) and are considered the most cytotoxic subset, while CD 56bright NK cells comprise approximately $10 \%$ of NK cells in PBMCs and are known as the cytokine-producing subset. NK cells play important role of the first line of defense to infected cells and transformed cells without prior sensitization (Hammer et al., 2018). CD56dimCD16+ NK cells (CD56dim NK cells) are cytotoxic NK cells which are able to cause

${ }^{1}$ Department of Biochemistry, Maulana Azad Medical College (MAMC) and Associated Hospitals, New Delhi, India. ${ }^{2}$ Multidisciplinary Research Unit (MRU), Maulana Azad Medical College and Associated Hospitals, Bahadur Shah Zafar Marg, New Delhi, 110002, India. ${ }^{3}$ Department of Gastroinstestinal Surgery G B Pant Postgraduate Institute of Medical Education and Research (GIPMER), New Delhi, India. ${ }^{4}$ Department of Medical Lab Technology, Faculty of Applied Medical Sciences, Prince Fahd Bin Sultan Research chair, University of Tabuk, Saudi Arabia.*For Correspondence: drrashidmamc@gmail.com.Biplob Kumar Biswas and Sameer Ahmad Guru have equal contribution in this study. 
direct target cell killing through exocytosis of granules containing granzyme B and perforin, activation of TRAIL or FAS/FAS-L cell death pathways or antibody dependent cellular cytotoxicity. CD56 bright CD16-/low NK cells (CD56bright NK cells) which are main cytokineproducing NK cells. Almost $90 \%$ of peripheral blood NK cells are CD56dim while CD56bright NK cells mainly reside in lymph nodes (Cooper et al., 2001). The functions of NK cells are regulated by activating and inhibitory receptor signals. In contrast to $\mathrm{T}$ cells, NK cells are ready to go and are able to eliminate target cells without prior stimulation. However, they come with enhanced functions only after activation by cytokines, in particular enhanced cytolytic activity and proliferation. NK cells are established potential candidates used for immunotherapy of cancer and their flexibility makes them attractive cells to explore. It has been reported that autologous NK cell therapies are feasible and safe without adverse effects in patients with non-Hodgkin's lymphoma and breast cancer (Burns et al., 2003). NK cell alloreactivity potential impact in haematopoietic stem cell transplantation (HSCT) was suggested by Valiante and Parham (1997). The proof that allogenic NK cells anti-leukemic activity and impact on the outcome of haploidentical transplantation comes from the studies of Ruggeri et al., (2002).

The field of NK cell based therapy has recently gained much interest and people are exploring the potential roles that NK cells are capable of playing in the treatment of various diseases (Welsh, 1978). Therefore, NK cell biology has expanded well beyond simply describing the cytotoxic functions of these cells, with new roles attributed to the collection of NK cell produced cytokines and the potential targets NK cells are able to recognize and bind (Cumulated Index Medicus, 1977) NK cells have been known to play important roles in not only viral and tumor resistance but also bacterial and fungal immune responses (Chalifour et al., 2004; Bouzani et al., 2011).NK cells have also been reported to be important in bone marrow rejections and cell engraftment as well (Li et al., 2013; Sun et al., 2012). A number of studies have reported that a variety cancer cell types including that of acute myeloid leukaemia, Hodgkin lymphoma, breast cancer, refractory lymphoma, ovarian and renal cell carncinoma can be targeted by allogeneic NK cells (Cumulated Index Medicus, 1992; Bachanova et al., 2010). Some studies have also shown the importance of NK cell expansion in vivo accomplished by infusion of interleukin-2 (IL-2) (Bachanova et al., 2014). NK cell therapy has also been reported to be of interest in treating glioma and neuroblastoma (Ishikawa et al., 2004; Tarek et al., 2012). Given the importance of NK cells as anti-cancer entities, a method of therapy that shall permit for the delivery of a large number of tumours naive activated NK cells to cancer patients and the ability to overcome the immunosuppressive tumour environment would have great potential (Gillgrass et al., 2011).

A sufficient amount of NK cells that too with a high cytotoxicity is required for conducting clinical applications about NK cell-based immunotherapy. Umbilical cord blood (UCB), bone marrow, peripheral blood (PB) and embryonic stem cells are the different sources for obtaining NK cells. Of these sources, UCB not only provides higher proportion of NK cells but is also an easy source of NK cell. Moreover, UCB can be stored and preserved for a long time to be used as readily source of NK-cell based therapy. Nevertheless, although UCB is having greater amount of NK cells in contrast to $\mathrm{PB}$, the number of NK cells actually obtained is really small because of the limited volume of UCB which presents a major hindrances in providing adequate amount of $\mathrm{NK}$ cells for clinical applications.

It was elucidated in our study that the NK cells can be differentiated from CD34+ cells isolated from cord blood and is capable to induce apoptosis with increased antitumor potential in vitro against different cancer cells via downregulation of survivin gene expression in tumor cells. Hence, following cytokine stimulation, the cytotoxicity of UCB NK cells can be rapidly increased to levels that are comparable to PB NK cells. Therefore, NK cell therapy represents a promising immunotherapy for different cancer types and haematological malignancies. Further studies are necessary to confirm our findings. Therefore, the aim of this study was to generate NK cells by invitro differentiation of human derived UCB CD34 cells and to expand these NK cells in vitro using the best available methodology and finally test the cytotoxic potential of these NK cells against different cancer cell lines.

\section{Materials and Methods}

\section{Methodology}

This study was conducted after the approval by the institutional ethics committee (IEC), MAMC and associated hospitals. This study was performed at the Department of Biochemistry in collaboration with Departments of Gynaecology and Pathology, Maulana Azad Medical College (MAMC) and Associated Hospitals, New Delhi, India

\section{Cell lines utilized}

Several cell lines were used in this study including -K562 (Chronic Myeloid Leukaemia), T47D (Human Breast Adenocarcinoma) -established from the pleural effusion of a ductal carcinoma of the breast of a 54-yearold female. The cells carry receptors for a variety of steroids.U87MG (Glioblastoma) and T47D (Human Breast Adenocarcinoma) used in this study were obtained from National Centre Cell for cell Science (NCCS), Pune, India. K562 and T-47D were cultured in Rosewell Park Memorial Institute (RPMI 1640) while U87 was cultured in Dulbecco's Modified Eagle's Medium (DMEM) media containing 10\% Fetal Bovine Serum, $100 \mathrm{U} / \mathrm{mL}$ Penicillin, $100 \mu \mathrm{g} / \mathrm{mL}$ Streptomycin, $250 \mathrm{ng} / \mathrm{mL}$ Amphotericin, 250 $\mu \mathrm{g} / \mathrm{mL}$ Gentamycin and $2 \mathrm{mM}$ L-glutamine. Cell lines were maintained at $37^{\circ} \mathrm{C}$ in a humid atmosphere containing 5\% $\mathrm{CO}_{2}$. On attaining 70-90\% confluence, subculturing was performed after cell counting and viability testing.

\section{Umbilical Cord Blood Collection}

Umbilical Cord Blood (UCB) units were obtained at birth on normal full term delivery after written informed consent regarding scientific use from Department of 
Gynaecology, Lok Nayak Jay Prakash (LNJP) Hospital (New Delhi, India). The use of these Umbilical Cord Blood (UCB) units for this research was approved by Institutional Ethics Review Board, Maulana Azad Medical College and Associated LNJP Hospital. After collection, the UCB samples were stored at room temperature and processed within 24 hours.

\section{Isolation of mononuclear cells from cord blood}

Once collected, the Umbilical Cord Blood (UCB) was separated out over a Ficoll Hypaque density gradient (Sigma). Ficoll Hypaque use is facilitated by Ficoll-Hypaque density gradient centrifugation-a simple and rapid method of purifying peripheral blood mononuclear cells (PBMC) that takes advantage of the density differences between mononuclear cells and other elements found in the blood sample. Thus, cells are distributed in the solution in layers based on the differences in their density/size. After centrifugation at $400 \mathrm{~g}$ for 40 minutes at $20^{\circ} \mathrm{C}$, the interface mononuclear cells were collected in separate tube, washed twice and were resuspended in Iscove's Modified Dulbecco's Media (IMDM) containing 20\% heat inactivated foetal calf serum. The cell viability was assessed by trypan blue exclusion test. The Trypan Blue dye exclusion test is used to determine the number of viable cells present in a cell suspension.

CD34+ CELLS COUNT : The presence of CD34+ cells was determined by microscopic immunoflorescence and flow cytometry (FCM).

Microscopic immunoflorescence: The CD34+ antigen is very highly expressed in pluripotent stem cells and its expression decreases gradually towards terminal differentiation into more mature cells. For immunoflorescence, monolayer of cell smear, without losing their morphology, was prepared using an auto slide smear system called cytocentrifuge. The cytocentrifuge is designed for concentration of biological samples on a visible surface for the microscope and its subsequent identification and characterisation. This reliable bench top centrifuge provides economical thin-layer preparations from any liquid matrix especially hypocellular fluid such as cell suspension. To prepare cell smear, the mononuclear cells were counted and viability assessed using Trypan blue exclusion assay. The cell concentration was 1,500 cells $/ \mu 1$ and we used $400 \mu \mathrm{l}$ cell suspensions for cyto-centrifugation. The contents were centrifuged at 2,000 rpm for 10 minutes. Next, the cells were fixed using $10 \%$ formaldehyde, prepared in PBS, for 10 minutes at room temperature. Blocking with $10 \% \mathrm{FBS}$ prepared in PBS was performed for 20 minutes at $37^{\circ} \mathrm{C}$ to minimize nonspecific adherence of antibodies and preventing generation of false positive signals. The blocking buffer was washed with $1 \mathrm{X}$ PBS before staining step. Finally, the smear was stained with conjugated primary antibodies for $1 \mathrm{hr}$. The slides were then washed three times for five minutes with $1 \mathrm{X}$ PBS and after drying the slides were visualised under florescent microscope.
Flow cytometric analysis for expression of $C D 56+C D 3-$ NK cells

NK T cells are a heterogeneous $\mathrm{T}$ cell population characterized by the co-expression of $\alpha \beta$ or $\gamma \delta$ TCRs and various NK receptors, including CD16, CD56, CD161, CD94, CD158a and CD158b . Human NK cells express CD16 and CD56 which are (massively) being used as a major hallmark for the NK cell. After performing cell counts and assessing cell viability, $100 \mu \mathrm{l}$ of cell sample suspension (density $1 \times 10^{2}$ cells $/ \mu \mathrm{l}$ ) was added to the fluorochrome-conjugated monoclonal antibodies; CD34-PE, anti-HLA-DR-FITC, CD45-ECD, CD3-PC5 and CD56-PC7 (Beckman Coulter, Inc).The antibodies were diluted in accordance with the manufacturer's specification. The samples were centrifuged at 1,500 rpm for 5 minutes after a dark incubation for 20 minutes. The suspension was removed after centrifugation and re-suspended with $1 \mathrm{ml}$ of isotone or sheath fluid for washing. After complete wash, the samples were put into Beckman Coulter Flow analyzer, the data acquired and analyses were performed.

Expansion of CD34+ progenitor cells and NK cell differentiation from cord blood mononuclear cells

a) Expansion of CD34+ UCB mononuclear cells:

Umbilical Cord Blood (UCB) mononuclear cells (density $1 \times 10^{5}$ cells $/ \mathrm{ml}$ ) were plated into $25 \mathrm{~cm}^{2}$ culture flasks in the Stemline IITM stem cell expansion medium containing $20 \mathrm{mg} / \mathrm{mL}$ ascorbic acid, $50 \mu \mathrm{mol} / \mathrm{L}$ ethanolamine, $50 \mu \mathrm{mol} / \mathrm{L}$ sodium selenite, $25 \mu \mathrm{mol} / \mathrm{L}$ $\beta$-mercapto-ethanol, $100 \mathrm{U} / \mathrm{mL}$ penicillin, $100 \mu \mathrm{g} / \mathrm{L}$ streptomycin and $2 \mathrm{mmol} / \mathrm{L}$ L-Glutamine. For each experiment, a $10 \mathrm{ml}$ of expansion medium was warmed to $37^{\circ} \mathrm{C}$. Five $\mathrm{ml}$ of the medium was pipette out in $25 \mathrm{~cm}^{2}$ culture plates to which $10 \%$ foetal bovin serum and a low dose cytokine cocktail consisting of $10 \mathrm{pg} / \mathrm{ml} \mathrm{GM-CSF}$, $250 \mathrm{pg} / \mathrm{ml} \mathrm{G}-\mathrm{CSF}, 50 \mathrm{pg} / \mathrm{ml} \mathrm{LIF}, 200 \mathrm{pg} / \mathrm{ml} \mathrm{MIP-} 1 \alpha$ and $50 \mathrm{pg} / \mathrm{ml}$ IL-6 was added. Cell culture was refreshed with new medium every 2-3 days and plates were maintained at $37^{\circ} \mathrm{C}$ in an atmosphere containing $5 \% \mathrm{CO}_{2}$ for 10 days. Following the incubation period, the expanded total nucleated cells were counted by using trypan blue assay and the differentiation step was monitored weekly, analyzed for cell numbers and cell surface marker CD34, HLA-DR, CD56, CD3 and CD56 using FCM.

\section{b) Differentiation of expanded cells into NK cell}

Expanded umbilical cord blood mononuclear cells were differentiated and further expanded using NK cell differentiation medium which consisted of same basal medium as used for expansion supplemented with $10 \%$ FBS, the low dose cytokine cocktail as previously mentioned and a new high dose cytokine cocktail which consisted of $20 \mathrm{ng} / \mathrm{mL}$ IL-7, $20 \mathrm{ng} / \mathrm{mL} \mathrm{SCF}, 1,000 \mathrm{U} / \mathrm{mL}$ IL-2 and $20 \mathrm{ng} / \mathrm{mL}$ IL-15. The medium was refreshed twice a week from day 10 onwards and plates were maintained at $37^{\circ} \mathrm{C}$ in an atmosphere containing $5 \%$ $\mathrm{CO}_{2}$ for 18 days. Cell number, expression of cell surface markers and purity was determined by FCM. 


\section{Cell proliferation assays}

Tumor cells (T47D, U87 and K562) were seeded at equal density $\left(1 \times 10^{5}\right.$ cells $\left./ \mathrm{ml}\right)$ in 96 well plates with appropriate medium and incubated at $37^{\circ} \mathrm{C}$ overnight prior to NK cell treatment. Next these tumor cells were treated with different density of NK cells $\left(1 \times 10^{4}, 2 \times 10^{4}\right.$, $4 \times 10^{4}$ cells $/ \mathrm{ml}$ ) and were further incubated for $48 \mathrm{hrs}$. All the treatments were performed in triplicates and repeated three times. Mean \pm SD for each NK cell treatment was determined. The cell viability was determined using MTT assay and apoptosis was measured with Annexin V-FITC assay.

\section{MTT assay}

The MTT assay is used to measure cellular metabolic activity as an indicator of cell viability, proliferation and cytotoxicity. Tetrazolium dye assays can also be used to measure cytotoxicity (loss of viable cells) or cytostatic activity (shift from proliferation to quiescence) of potential medicinal agents and toxic materials. MTT assays are usually done in the dark since the MTT reagent is sensitive to light. The colorimetric MTT assay based on selective ability of living cells to reduce the yellow salt MTT [3-(4,5-dimethylethiazol-2,5-diphenyltetrazolium bromide] to formazan, was used as a cytotoxicity assay according to the standardized protocol. Briefly, after incubation period of tumor cell treatment with different NK cell density $10 \mu \mathrm{L}$ of MTT (Sigma M2128, $5 \mathrm{mg} / \mathrm{ml}$ ) was added to each well and incubated for $2 \mathrm{hrs}$ at $37^{\circ} \mathrm{C}$ and $5 \% \mathrm{CO}_{2}$. After two hour incubation, the fomazan crystals were dissolved in $150 \mu \mathrm{L} /$ well dimehtylsulphoxide $(100 \%$; Sigma D 8779 ACS). The absorbance was recorded on microplate spectrophotometer (Titertek Multiscan MCC 340, Flow Laboratory) at a wave length of $570 \mathrm{~nm}$. Cell viability (in percentage, \%) was depicted as ratio of absorbance (A570nm) in treated cells to absorbance in control cells (DMSO) (A570 nm).

Cell viability $(\%)=$ A570nm $($ Sample $) /$ A570nm (Control DMSO) X 100

Flow cytometry measurement of apoptosis (Annexin V-FITC assay):

Equal density $\left(1 \times 10^{5} \mathrm{cell} / \mathrm{s} / \mathrm{ml}\right)$ of tumor cells treated with different NK cell density as described above. After designated time, cells were harvested from each experiment group and stained with FITC-annexin V and PI (BD Biosciences) in binding buffer for 15 minutes. Stained cells were immediately subjected to flow cytometry analyses.

\section{Quantitative real time PCR ( $q R T-P C R$ ) analysis for survivin expression}

Cells from each treatment and control groups were harvested and processed for total RNA extraction using Trizol reagent for total RNA extraction. RNA quality was checked by agarose gel electrophoresis and quantified using NanoDrop technology (Washington, DE, USA; SA Guru.,et al 2017). Complimentary DNA (cDNA) synthesis was performed by reverse transcribing 100ng/ $\mu \mathrm{L}$ RNA using cDNA kit (Thermo Fisher Scientific, USA) according to the instructions provided. Briefly, RNA was mixed with the cDNA synthesis reagents to a final concentration of $100 \mathrm{ng} / \mu \mathrm{L}$ in a final reaction mixture of $20 \mu \mathrm{L}$. A particular volume of RNA was mixed with $2 \mu \mathrm{L}$ of random hexamer and the volume was made up to 12 $\mu \mathrm{L}$. This $12 \mu \mathrm{L}$ reaction volume was incubated at $72^{\circ} \mathrm{C}$ for 5 minutes in a thermocycler. After the incubation step, $8 \mu \mathrm{L}$ cDNA synthesis cocktail containing $4 \mu \mathrm{L}$ cDNA buffer, $2 \mu \mathrm{L}$ dNTPs, $1 \mu \mathrm{L}$ reverse transcriptase enhancer and $1 \mu \mathrm{L}$ reverse transcriptase was mixed with $12 \mu \mathrm{L}$ RNA premix. The final reaction mixture $(20 \mu \mathrm{L})$ was incubated at $42^{\circ} \mathrm{C}$ for $1 \mathrm{hr}$ and at $95^{\circ} \mathrm{C}$ for 5 minutes. The cDNA was kept at $-80^{\circ} \mathrm{C}$ until used. The quantitative real time PCR (qRT-PCR) was carried out on Rotor-Gene Instrument (QIAGEN; Skelton House, Lloyd, Manchester,UK) and consisted of same steps as mentioned in our published study (Baginska et al., 2013) for evaluating expression levels of suvivin gene. The $\beta$-actin gene was used as reference housekeeping for normalisation. The primer sequences used were: Survivin F-5'CAGATTTGAATCGCGGGACCC3' and R-5' CCAAGTCTGGCTCGTTCTCAG 3' for $\beta$-actin-F ( $5^{\prime}$-CGACAACGGCTCCGGCATGTGC-3') and $\beta$-actin-R (5'-GTCACCGGAGTCCATCACGATGC-3'). Briefly, the temperature profile consisted of three segments: the first segment of the amplification cycle consisted of a denaturation program of $95^{\circ} \mathrm{C}$ for 10 minutes. The second segment consisted of three steps: denaturation $\left(94^{\circ} \mathrm{C}\right.$ for 15 seconds), primer annealing $\left(58^{\circ} \mathrm{C}\right.$ for 45 seconds), and elongation $\left(72^{\circ} \mathrm{C}\right.$ for 45 seconds) which was repeated for 40 cycles. The final segment consisted of a melting curve program (ranging from $35^{\circ} \mathrm{C}$ to $95^{\circ} \mathrm{C}$ ).

\section{Statistical analysis}

Statistical analysis performed using the SPSS 16.0 software package. Chi-square analysis and Fisher exact test. The $\mathrm{p}$ value was considered to be significant when $<0.05$.

\section{Results}

Ex vivo Progenitor Cell Expansion and NK Cell Differentiation

After the isolation of mononuclear cells from

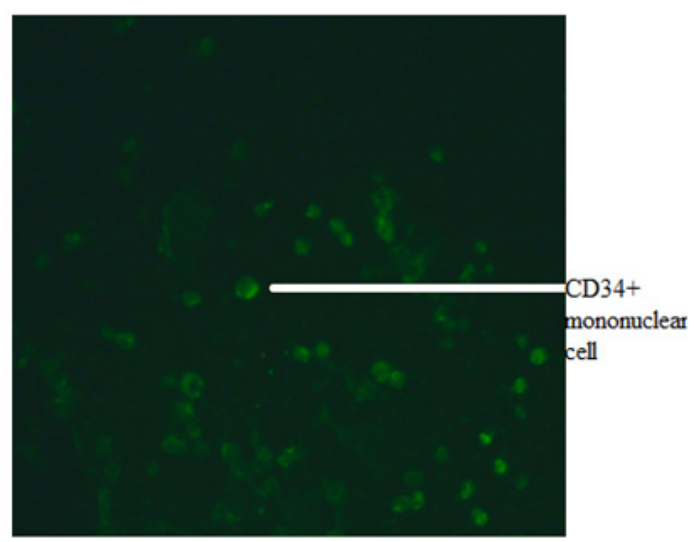

Figure 1. Immunofluorescence Picture of CD34+ Positive Mononuclear Cells 


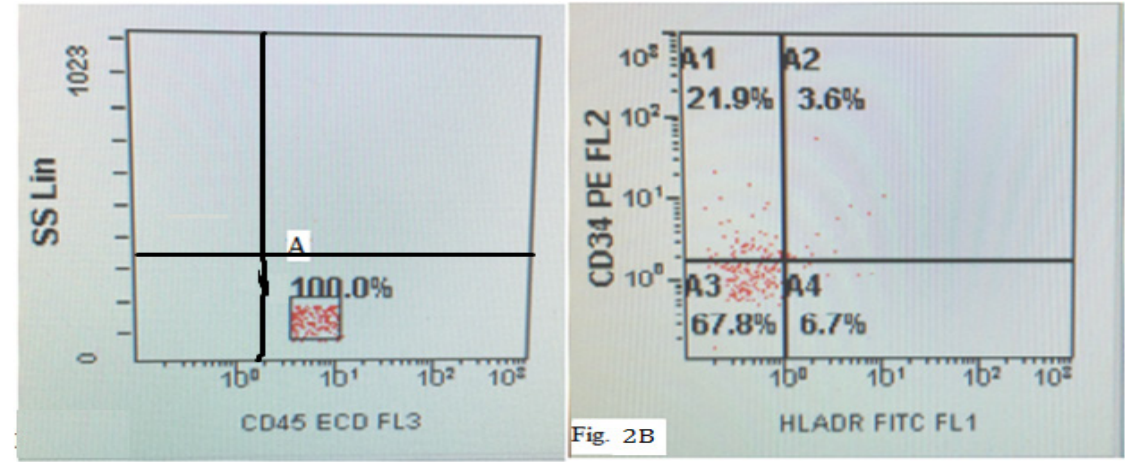

Figure 2. An Initial Gate (A) is set on a CD45-ECD vs SSC dot plot, so as to contain all CD45dim and CD45 bright .This exclude CD45 negative events(i.e,red cells, platelets and other debris) Fig 2B :CD34+-PE vs HLADR-FITC dot plot and event in gate A1 shows $21.9 \%$ of positive CD34+ cells Gate A4 shows $6.7 \%$ of HLADR positive cells white gate $\mathrm{A} 2$ displayed $3.6 \%$ of both $\mathrm{CD} 34+$ and HLADR positive cells

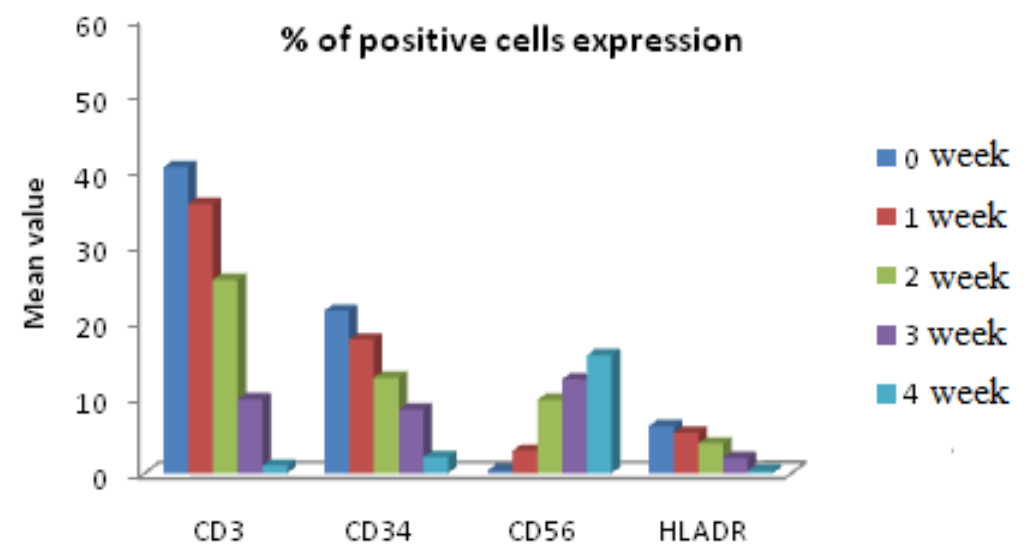

Figure 3. In vitro Generation of CD56 Positive Cells from Cytokine Expanded CD34+ Postive UCB Cells

Table 1. Fold Expansion of Total Cells During 4 Week of Culture

\begin{tabular}{lcc}
\hline Group & $\begin{array}{c}\text { Mean fold expansion } \pm \text { SD } \\
(\mathrm{n}=4)\end{array}$ & $\begin{array}{c}95 \% \text { confidence } \\
\text { interval }\end{array}$ \\
\hline 1 week & $36.750 \pm 8.421$ & $23.352-50.148$ \\
2 week & $108.00 \pm 9.092$ & $93.535-122.47$ \\
3 week & $612.50 \pm 158.82$ & $359.82-865.18$ \\
4 week & $1925.0 \pm 434.93$ & $1233.0-2617.0$ \\
\hline
\end{tabular}

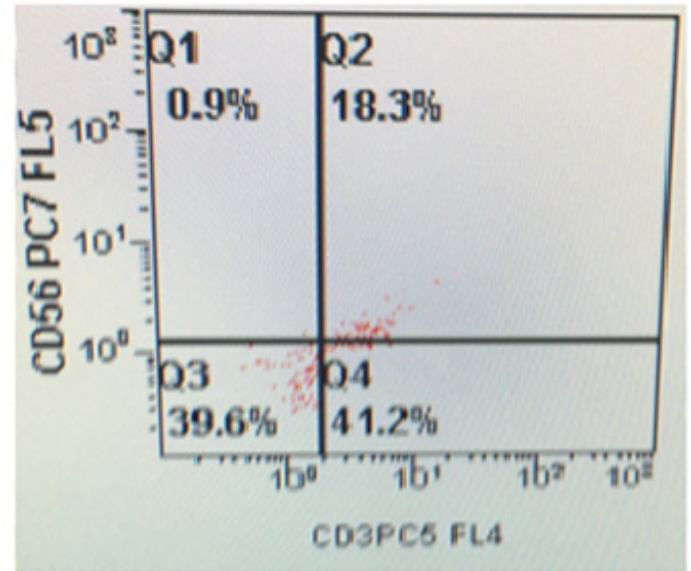

Figure 4. The Event in Gate Q1 Shows $0.9 \%$ of CD56 Positive NK Cells while Gate Q4 Shows $41.2 \%$ of Positive CD3 Expression during 0 Week Culture fresh obtained cord blood, we first determined the CD 34+ surface marker MNCs using immunoflorescence (Figure 1). Flowcytometric analysis revealed the CD34+ mononuclear cells during 0 week of culture as depicted in Figure (Figures 2A, 2B). This was followed by culturing these UCB-CD34+ cells with Stemline IITM stem cell expansion medium for four weeks. The CD34+ UCB cells were expanded and differentiated into NK cells which followed by $\log$ scale generation of CD56+CD3- NK cells. The differentiation step was monitored weekly

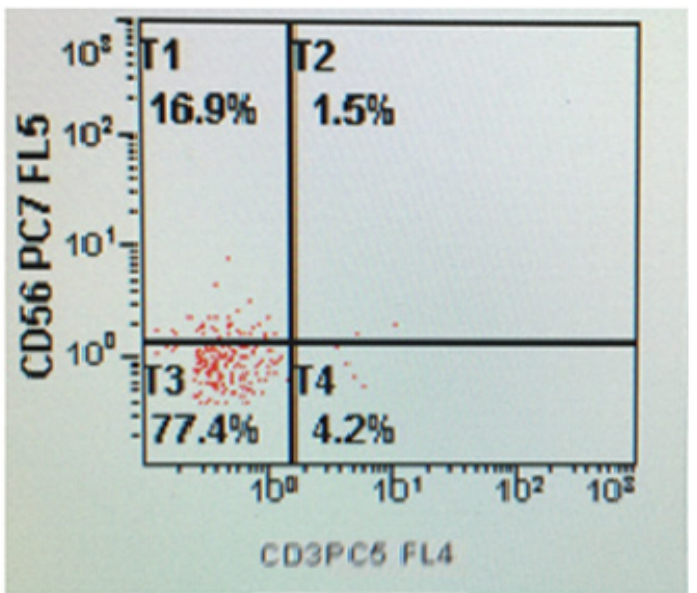

Figure 5. The Event in Gate T1 Shows $16.9 \%$ of CD56 Positive NK Cells after 4 Week of Cell Culture of UCB Mononuclear Cells 
Table 2. Mean Percentage of Apoptotic Cells in NK Cells Treated Tumour Cells at Different NK Cell Concentrations A. Group $=$ NK Cells on T47D

\begin{tabular}{lccccc}
\hline & Mean & Std. Deviation & Std. Error & \multicolumn{2}{c}{$95 \%$ Confidence Interval for Mean } \\
& & & & Lower Bound & Upper Bound \\
\hline 10,000 cells $/ \mathrm{ml}$ & 5.3333 & 1.26623 & 0.73106 & 2.1878 & 8.4788 \\
20,000 cells $/ \mathrm{ml}$ & 8.3333 & 0.70946 & 0.40961 & 6.5709 & 10.0957 \\
40,000 cells $/ \mathrm{ml}$ & 13.8 & 0.6245 & 0.36056 & 12.2487 & 15.3513 \\
Control & 0.4 & 0.2 & 0.11547 & -0.0968 & 0.8968 \\
\hline
\end{tabular}

B. Group $=$ NK Cells on U87

\begin{tabular}{lccccc}
\hline & Mean & Std. Deviation & Std. Error & \multicolumn{2}{c}{$95 \%$ Confidence Interval for Mean } \\
& & & & Lower Bound & Upper Bound \\
\hline 10,000 cells $/ \mathrm{ml}$ & 5.6667 & 1.30512 & 0.75351 & 2.4246 & 8.9088 \\
20,000 cells $/ \mathrm{ml}$ & 8.8333 & 0.41633 & 0.24037 & 7.7991 & 9.8676 \\
40,000 cells $/ \mathrm{ml}$ & 12.8333 & 1.2897 & 0.74461 & 9.6295 & 16.0371 \\
Control & 0.4 & 0.36056 & 0.20817 & -0.4957 & 1.2957 \\
\hline
\end{tabular}

C. Group $=$ NK Cells on K562

\begin{tabular}{lccccc}
\hline & Mean & Std. Deviation & Std. Error & \multicolumn{2}{c}{$95 \%$ Confidence Interval for Mean } \\
& & & & Lower Bound & Upper Bound \\
\hline 10,000 cells $/ \mathrm{ml}$ & 4.6333 & 1.16762 & 0.67412 & 1.7328 & 7.5339 \\
20,000 cells $/ \mathrm{ml}$ & 8.9667 & 1.51438 & 0.87433 & 5.2047 & 12.7286 \\
40,000 cells $/ \mathrm{ml}$ & 15 & 0.26458 & 0.15275 & 14.3428 & 15.6572 \\
Control & 0.5 & 0.36056 & 0.20817 & -0.3957 & 1.3957 \\
\hline
\end{tabular}

and analysed for cell numbers and cell surface markers CD34, HLA-DR, CD56 and CD3 using FCM. Data were depicted as mean $\pm \mathrm{SD}$. The mean total cell expansion for all experiments $(\mathrm{n}=$.) was $21.4 \pm 0.5,17.6 \pm 1,12.6 \pm 0.8$,.and fold after $0,1,2,3$ and 4 weeks respectively (Figure 3 ). We next differentiated CD34+ UCB cells into CD56+ CD3NK cells. First differentiation process was continued in the same expansion medium as used for CD 34+ cell expansion process followed by addition of NK cell differentiation medium which consisted of same basal medium as used for expansion supplemented with $10 \%$ FBS, the low dose cytokine cocktail as previously mentioned and a new high dose cytokine cocktail which consisted of 20 $\mathrm{ng} / \mathrm{mL} \mathrm{IL}-7,20 \mathrm{ng} / \mathrm{mL} \mathrm{SCF}, 1,000 \mathrm{U} / \mathrm{mL}$ IL-2 and 20

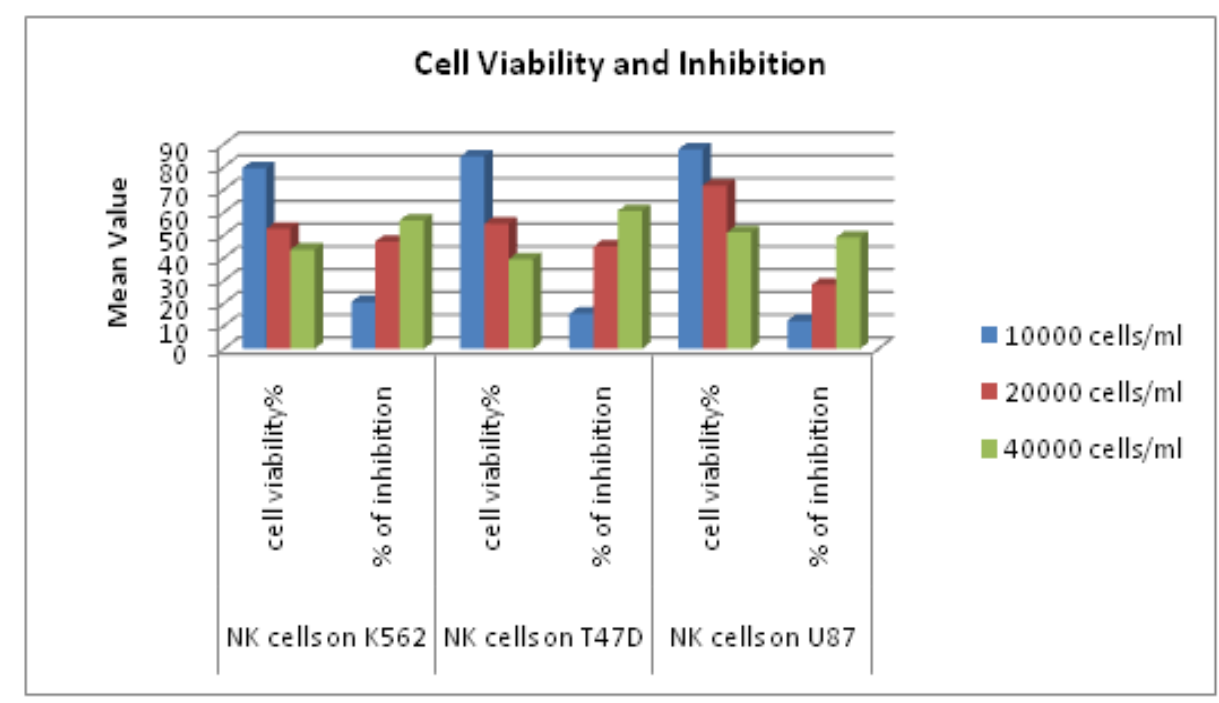

Figure 6. Show Percentage of Cell Viability and Inhibition of NK Cells Treated Different Tumor Cell Lines .Antitumor activity of NK cell against T47D,NK cells against U87. A: Four hour cytotoxicity against K562 cell lines with NK cells . Mean of four measurements at each E:T ration B : Four hour cytotoxicity OF NKAES-NK cells from 4 donors against AML cells from 2 patients. C: Cytotoxicity against AML cells from 5 patients after 5D of culture on MSC. Mean + SD cells killing at the indicated E:T ratios in triplicate cultures Mean +SD cells killing at the indicated E:T ratios in triplicate cultures 


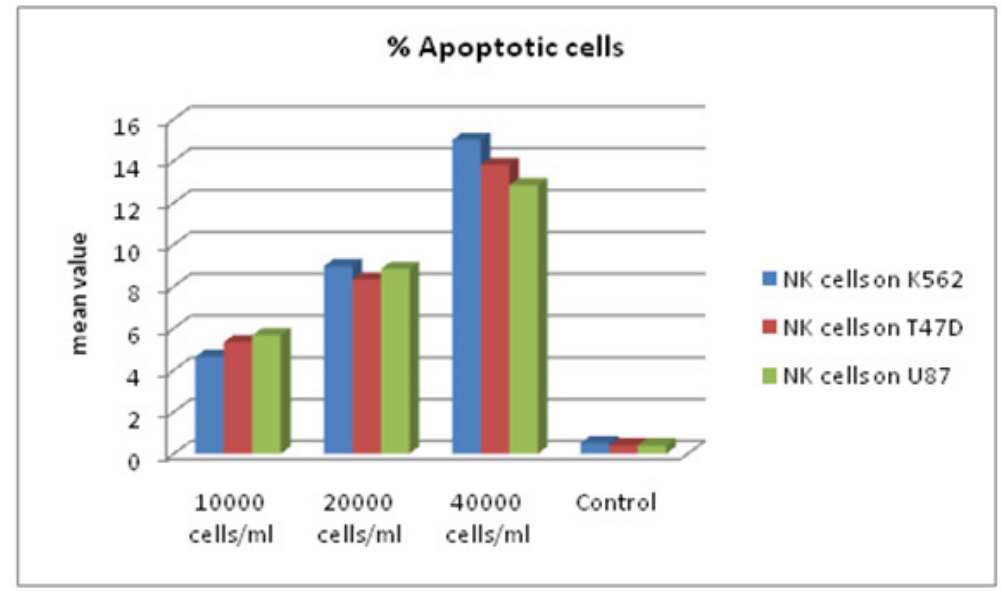

Figure 7 A. Flow Cytometric Analysis of Apoptosis of Different Tumor Cells Treated with NK Cells. The cells were stained with Annexin V-FITC and PI.The event in gate A 1 show \% of necrotic cells stained with PI and gate A3 shows $\%$ of viable cells. While gate A2 and A4 exhibit \% of late apoptosis $(0.7 \%)$ and early apoptosis $(18.1 \%)$ respectively stained with Annexin V.
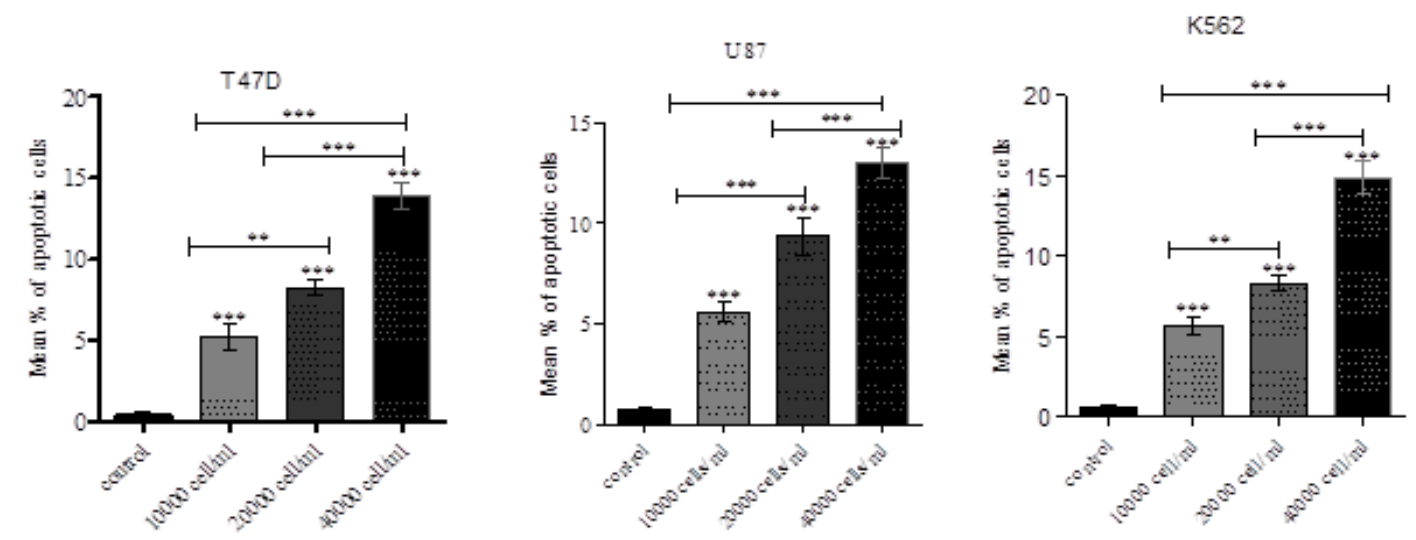

Figure 8A. Mean \% of Apoptosis in Different Tumor Cells .Mean \% of apoptosis increased significantly in all treatment doses. Flow cytometric analysis of apoptosis of different tumor cells treated with NK cells .8B: Mean \% of apoptosis in different in different tumor cells. Mean \% of apoptosis increased significantly in all treatments doses.

$\mathrm{ng} / \mathrm{mL}$ IL-15. The medium was refreshed twice a week from day 10 onwards and plates were maintained at $37^{\circ} \mathrm{C}$ in an atmosphere containing $5 \% \mathrm{CO}_{2}$ for 18 days. Cell number, expression of cell surface markers and purity was determined by FCM as depicted in Figures 4 and 5. The mean fold expansion of total cells after initial seeding of 1x $10^{5}$ cord blood mononuclear cells $/ \mathrm{ml}$ was determined during 4 week of culture and the results are represented as mean \pm SD of 4 different experiments as shown in Table 1 and also in Figure 6).

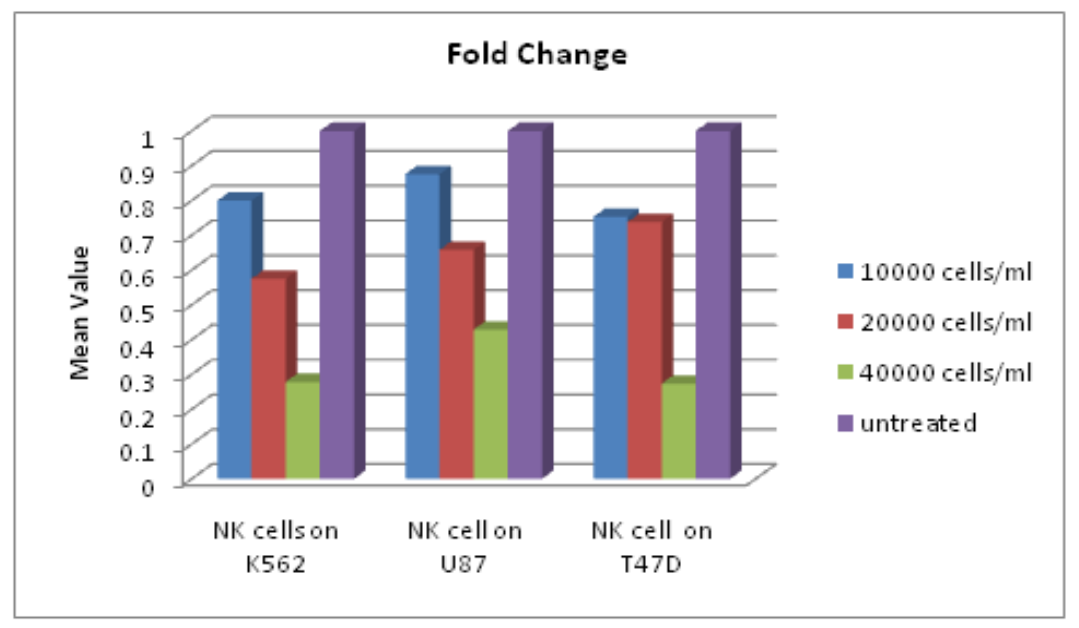

Figure 9. Shows Fold Change of Survivin Expression of NK Cells Treated Tumor Cells 
Table 3. Mean Expression of Survivin m-RNA after NK Cell Treatment

A. group $=$ NK cell on T47D

\begin{tabular}{lccccc}
\hline & Mean & Std. Deviation & Std. Error & \multicolumn{2}{c}{ 95\% Confidence Interval for Mean } \\
& & & & Lower Bound & Upper Bound \\
\hline 10,000 cells $/ \mathrm{ml}$ & 0.7528 & 0.16314 & 0.09419 & 0.3475 & 1.158 \\
20,000 cells $/ \mathrm{ml}$ & 0.7378 & 0.14967 & 0.08641 & 0.366 & 1.1096 \\
40,000 cells $/ \mathrm{ml}$ & 0.2737 & 0.24355 & 0.14061 & -0.3313 & 0.8788 \\
untreated & 1 & 0 & 0 & 1 & 1 \\
\hline
\end{tabular}

B. group $=$ NK cell on $\mathrm{U} 87$

\begin{tabular}{lccccc}
\hline & Mean & Std. Deviation & Std. Error & \multicolumn{2}{c}{$95 \%$ Confidence Interval for Mean } \\
& & & & Lower Bound & Upper Bound \\
\hline 10,000 cells $/ \mathrm{ml}$ & 0.8758 & 0.15142 & 0.08742 & 0.4996 & 1.2519 \\
20,000 cells $/ \mathrm{ml}$ & 0.6579 & 0.16215 & 0.09362 & 0.2551 & 1.0607 \\
40,000 cells $/ \mathrm{ml}$ & 0.4289 & 0.12873 & 0.07432 & 0.1091 & 0.7487 \\
untreated & 1 & 0 & 0 & 1 & 1 \\
\hline
\end{tabular}

C. group $=$ NK cells on K562

\begin{tabular}{lccccc}
\hline & Mean & Std. Deviation & Std. Error & \multicolumn{2}{c}{$95 \%$ Confidence Interval for Mean } \\
& & & & Lower Bound & Upper Bound \\
\hline 10,000 cells $/ \mathrm{ml}$ & 0.7998 & 0.05708 & 0.03296 & 0.658 & 0.9416 \\
20,000 cells $/ \mathrm{ml}$ & 0.575 & 0.12502 & 0.07218 & 0.2645 & 0.8856 \\
40,000 cells $/ \mathrm{ml}$ & 0.2785 & 0.06745 & 0.03894 & 0.1109 & 0.4461 \\
untreated & 1 & 0 & 0 & 1 & 1 \\
\hline
\end{tabular}

Cytotoxicity of expanded NK cells against different tumour cells

The cytotoxicity of NK cells expanded and differentiated from UCB was tested against different tumour cell lines such as K562 (AML cell line), U87 (Glioblastoma cell line), T47D (Breast cancer cell line). Two hundred microliters of an exponentially growing tumor cell suspension was seeded in a 96-well plate and NK cell were added at various concentrations $\left(1 \times 10^{4}\right.$, $2 \times 10^{4}$ and $4 \times 10^{4}$ cells $\left./ \mathrm{ml}\right)$. Each experiment was carried out thrice in pentaplicate for each concentration. We found that NK cells were consistently cytotoxic against all the target tumour cells with maximum cytotoxicity obtained against U87 glioblastoma cell line (Figure 6). Results are expressed as mean $\pm \mathrm{SD}$.

Annexin V Apoptosis Detection Using Untreated and NK cell-Treated tumour Cells

Apoptosis of target tumour cells induced by NK cells was analysed. Untreated and NK cell treated K562, U87 and T47D cells were stained using Annexin V FITC apoptosis detection kit. Data from the untreated and treated samples were obtained using Annexin V FITC assay. Figure 7 plots were used for gating cells and to identify any changes in the scatter properties of the cells. Annexin V FITC vs Propidium Iodide plots from the gated cells exhibit the populations corresponding to viable and non-apoptotic (V-PI-), early apoptosis (Annexin V+ PI-)
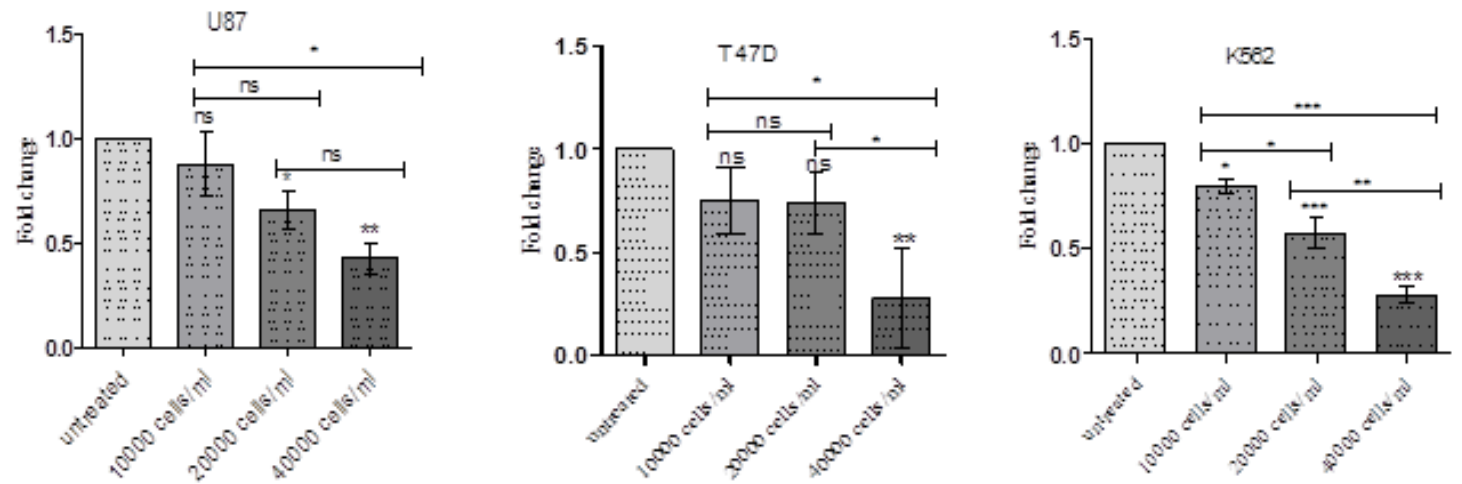

Figure 10. NK Cells Significantly Reduce Survivin Gene Expression in Different Cancer Cell Lines in vitro and the Reduction was Observed to be more on Increasing NK Cell Proportion 
and late apoptotic cells (Annexin $\mathrm{V}+\mathrm{PI}+$ ).In the untreated (control) samples, the majority of cells ( $>95 \%$ ) were viable and non-apoptotic (Annexin V- PI-). In contrast to cells that were treated with NK cells with different effector: target ratios for cell lines. (Time duration of treatment) we found corresponding and significant decrease in mean percentage of viable cells (Annexin V-PI-) with increase in effector NK cells in all the target tumour cells. There was an increase in early apoptotic cell populations (Annexin V+ PI-) from untreated to treated cells. A slight increase in the Annexin $\mathrm{V}+\mathrm{PI}+$ cell population was also identified, indicating late apoptosis or dead cells. The increase in apoptotic cells was also reflected by changes in the pattern of light scatter properties for the untreated and treated groups. During apoptosis, cell shrinkage is associated with decrease in forward scatter. Moreover, the formation of apoptotic vesicles in the cells during apoptosis leads to an increased side scatter profile as depicted in Tables 2A, $2 \mathrm{~B}, 3 \mathrm{C}$ and also presented in Figures 7 and $8 \mathrm{~A}$ and $8 \mathrm{~B}$ ).

\section{NK cell treatment and Survivin expression in tumour cell lines}

We analysed the effect of NK cell treatment on survivin gene expression in different tumour cells K562, U87 and T47D in vtro. We observed that survivin gene expression decreased in tumor cells on treatment with NK cells. Further, it was identified that there was a progressive and statistically significant decrease in survivin gene expression with increasing NK cell dose. The results are expressed as mean $\pm \mathrm{SD}$ and represented in Tables $3 \mathrm{~A}, 3 \mathrm{~B}$, 3C and Figures 9 and 10.

\section{Discussion}

Cancer immunosurveillance is a protective mechanism of the body against cancer and a major role is played by natural killer cells. NK cells are the first line defence mechanism against malignant transformed and virally infected cells (Conlon et al., 2015).However, malignant cells evolve a mechanism to evade the defence mechanisms of immune system and create an immunosuppressive microenvironment (Almand et al., 2001; Deng et al., 2013). This is brought out by secreting some factors such as MICA, MICB and vesicles containing ULBP3, by tumour cells which impair cytotoxic ability of NK cells thus facilitating immune evasion (Ib et al., 2011; Fernández-Messina et al., 2010).

In addition, NK cells also secrete tumour cell-derived factors and tumour derived exosomes which further suppress NK cell activity (Baginska et al., 2013). All of these factors cause decreased expression of activating receptors on NK cells while increasing expression of the receptors having an inhibitory role (Ib et al., 2011; Fernández-Messina et al., 2010). Several studies have identified that invitro expanded NK cells have an increased cytotoxic efficiency and can be used for cancer treatment (Mamessier et al., 2011; Ascierto et al., 2013). It has been identified that expanded NK cells from healthy donors possess higher cytotoxic potentials than NK cells isolated from cancer patients (Denman et al., 2012; Lim et al., 2013). The aim of this study was to explore the cytolytic activities of cord blood derived CD34+ differentiated and invitro expanded NK cells. The cytolytic activities of these expanded NK cells were tested against K562 leukemic cell lines, T47D breast cancer cell lines and U87 glioma cell lines.

Our results indicate that expanded NK cells exhibit almost similar cytolytic effects on all the three types of cells used in this study although a slightly higher level of cytolytic activity was observed against K562 leukemic cell lines. Previous studies report that expanded NK cells show variable cytotoxicity against different cancer cell lines (Berg et al., 2009). The expanded NK cells have been reported to attack primary patient cells isolated from acute myeloid leukaemia and chronic myeloid leukaemia patients (Tanaka et al., 2012; Mir et al., 2017). CML is a hematopoietic stem-cell disorder and is induced by the $\mathrm{BCR}-\mathrm{ABL}$ oncogene, whose gene product is a BCRABL tyrosine kinase. The inability of BCR-ABL kinase inhibitors to completely kill leukemia stem cells (LSCs) indicates that these kinase inhibitors are unlikely to cure CML (Mir et al., 2015, Mir et al., 2015).

The use of invitro expanded NK cells is gaining importance as cancer immune therapeutic strategy.

Allogeneic NK cells have been observed to have strong anticancer effects after haploidentical hematopoietic stem cell transplantation (haplo-HCT) in patients with advanced AML (Ruggeri et al., 2002). Haplo-HCT has been suggested as a viable treatment option for AML patients lacking a matched sibling donor and peripheral blood is being suggested to be considered as graft source for haplo-HCT with acceptable post-transplant outcomes (38).

The mechanisms employed for evading immune surveillance by cancer cells include among others down regulation of surface expression of NKG2D ligands ULBP1, ULPB2 and MICA. These ligands help NK cells to recognize tumour cells and render them susceptible to cytolysis (Rashidi et al., 2016). A large number of studies are being performed presently to unravel the innate immune mechanisms for target cell recognition on one hand and the multifaceted lytic machinery of NK cells on the other hand. The ability of manipulating not only the balance of receptors involving activating and inhibitory signals in NK cells but also their cognate ligands and the sensitivity of tumour cells to apoptosis will lead to new perspectives in NK cell based immunotherapy.

In conclusion, our finding indicated that NK cells differentiated from CD34+ cells isolated from cord blood were able to induce apoptosis and has shown increased antitumor potential in vitro against different cancer cells besides cause down regulation of survivin gene expression in tumor cells. Therefore, NK cell therapy represents a promising immunotherapy for cancers like AML and other haematological malignancies. Furthers studies are necessary to confirm our findings.

\section{Acknowledgements}

We are grateful to the patients for providing umbilical cord blood with whose cooperation this study was possible and National Centre Cell for cell Science (NCCS), Pune, India for providing cell lines. We are highly thankful to

Asian Pacific Journal of Cancer Prevention, Vol $21 \mathbf{1 6 0 3}$ 
Multidisciplinary Research Unit (MRU), Maulana Azad Medical College and Associated Hospitals, Bahadur Shah Zafar Marg, New Delhi, 110002, India for providing us Laboratory facilities.

\section{Disclosure}

This manuscript is not under consideration by any other publication and has not been published elsewhere. Authors have declared that no competing interests exist.

\section{References}

Almand B, Clark JI, Nikitina E, et al (2001). Increased production of immature myeloid cells in cancer patients: a mechanism of immunosuppression in cancer. J Immunol Baltim Md 1950, 166, 678-89.

Ascierto ML, Idowu MO, Zhao Y, et al (2013). Molecular signatures mostly associated with NK cells are predictive of relapse free survival in breast cancer patients. $J$ Transl Med, 11, 145.

Bachanova V, Burns LJ, McKenna DH, et al (2010). Allogeneic natural killer cells for refractory lymphoma. Cancer Immunol Immunother CII, 59, 1739-44.

Bachanova V, Cooley S, Defor TE, et al (2014). Clearance of acute myeloid leukemia by haploidentical natural killer cells is improved using IL-2 diphtheria toxin fusion protein. Blood, 123, 3855-63.

Baginska J, Viry E, Paggetti J, Medves S, et al (2013). The critical role of the tumor microenvironment in shaping natural killer cell-mediated anti-tumor immunity. Front Immunol, 4, 490.

Berg M, Lundqvist A, McCoy P, et al (2009). Clinical-grade ex vivo-expanded human natural killer cells up-regulate activating receptors and death receptor ligands and have enhanced cytolytic activity against tumor cells. Cytotherapy, 11, 341-55.

Bouzani M, Ok M, McCormick A, et al (2011). Human NK cells display important antifungal activity against Aspergillus fumigatus, Which is directly mediated by IFN- $\gamma$ release. J Immunol, 187, 1369-76.

Burns LJ, Weisdorf DJ, DeFor TE, et al (2003). IL-2-based immunotherapy after autologous transplantation for lymphoma and breast cancer induces immune activation and cytokine release: a phase I/II trial. Bone Marrow Transplant, 32, 177-86.

Cerwenka A, Lanier LL (2016). Natural killer cell memory in infection, inflammation and cancer. Nat Rev Immunol, 16, 112-23.

Chalifour A, Jeannin P, Gauchat J-F et al (2004). Direct bacterial protein PAMP recognition by human NK cells involves TLRs and triggers alpha-defensin production. Blood, 104, 1778-83.

Conlon KC, Lugli E, Welles HC, et al (2015). Redistribution, hyperproliferation, activation of natural killer cells and CD8 T cells, and cytokine production during first-in-human clinical trial of recombinant human interleukin-15 in patients with cancer. J Clin Oncol, 33, 74-82.

Cooper MA, Fehniger TA, Caligiuri MA (2001). The biology of human natural killer-cell subsets. Trends Immunol, 22, 633-40.

Cumulated Index Medicus. U.S. Department of Health and Human Services, Public Health Service, National Institutes of Health, National Library of Medicine; 1977.760 p.

Cumulated Index Medicus. U.S. Department of Health and Human Services, Public Health Service, National Institutes of Health, National Library of Medicine; 1992. 1444 p.

Deng B, Zhu J-M, Wang Y, et al., (2013). Intratumor hypoxia promotes immune tolerance by inducing regulatory $\mathrm{T}$ cells via TGF- $\beta 1$ in gastric cancer. gangopadhyay $\mathrm{N}$, editor. $P L o S$ One, 8, e63777.

Denman CJ, Senyukov VV, Somanchi SS, et al (2012). Membrane-bound IL-21 promotes sustained ex vivo proliferation of human natural killer cells. PLoS One, 7, e30264.

Diaz-Montero CM, Salem ML, Nishimura MI, et al (2020). Increased circulating myeloid-derived suppressor cells correlate with clinical cancer stage, metastatic tumor burden, and doxorubicin-cyclophosphamide chemotherapy. Cancer Immunol Immunother, 58, 49-59.

Fernández-Messina L, Ashiru O, Boutet P, et al (2010). Differential Mechanisms of Shedding of the Glycosylphosphatidylinositol (GPI)-anchored NKG2D Ligands. J Biol Chem, 19, 8543-51.

Gillgrass A, Ashkar A (2011). Stimulating natural killer cells to protect against cancer: recent developments. Expert Rev Clin Immunol, 7, 367-82.

Hammer Q, Rückert T, Romagnani C (2018). Natural killer cell specificity for viral infections. Nat Immunol, 19, 800-8.

Hilpert J, Grosse-Hovest L, Grünebach F, et al (2012). Comprehensive analysis of NKG2D ligand expression and release in leukemia: implications for NKG2D-mediated NK cell responses. J Immunol Baltim Md 1950, 189, 1360-71.

Ib B, Tk H, X L, et al (2011). Hypoxia induces escape from innate immunity in cancer cells via increased expression of ADAM10: Role of Nitric Oxide Cancer research. Cancer Res, 71, 17.

Ishikawa E, Tsuboi K, Saijo K, et al (2004). Autologous natural killer cell therapy for human recurrent malignant glioma. Anticancer Res, 24, 1861-71.

Kronstad LM, Seiler C, Vergara R, Holmes SP, Blish CA (2018). Differential induction of IFN- $\alpha$ and modulation of CD112 and CD54 expression govern the magnitude of NK cell IFN- $\gamma$ response to Influenza A Viruses. J Immunol Baltim Md 1950, 201, 2117-31.

Li SS, Kyei SK, Timm-McCann M, et al (2013). The NK receptor NKp30 mediates direct fungal recognition and killing and is diminished in NK cells from HIV-infected patients. Cell Host Microbe, 14, 387-97.

Lim SA, Kim T-J, Lee JE, et al (2013). Ex vivo expansion of highly cytotoxic human NK cells by cocultivation with irradiated tumor cells for adoptive immunotherapy. Cancer Res, 73, 2598-607.

Mamessier E, Sylvain A, Thibult M-L, et al (2011). Human breast cancer cells enhance self-tolerance by promoting evasion from NK cell antitumor immunity. J Clin Invest, 121, 3609-22.

Mir R, Ah I, Javid J, et al (2015). Polymorphism T81C in H-RAS oncogene is associated with disease progression in imatinib (TKI) treated chronic myeloid leukemia patients. World $J$ Oncol, 6, 321-8.

Mir R, Ahmad I, Javid J, et al (2015). Simple multiplex RT-PCR for identifying common fusion BCR-ABL transcript types and evaluation of molecular response of the $a 2 b 2$ and $a 2 b 3$ transcripts to Imatinib resistance in north Indian chronic myeloid leukemia patients. Indian J Cancer, 52, 314-8.

Mir R, Najar IA, Guru S, et al (2017). A deletion polymorphism in the RIZ gene is associated with increased progression of imatinib treated chronic myeloid leukemia patients. Leuk Lymphoma, 58, 1694-1701.

Paul S, Lal G (2017). The molecular mechanism of natural killer cells function and its importance in cancer immunotherapy. Front Immunol [Internet], 2017 Sep 13.

Rashidi A, DiPersio JF, Westervelt P, et al (2016). Comparison of outcomes after peripheral blood haploidentical versus matched unrelated donor allogeneic hematopoietic cell 
transplantation in patients with acute myeloid leukemia: A retrospective single-center review. Biol Blood Marrow Transplant, 22, 1696-701.

Rezvani K, Rouce RH (2015). The application of natural killer cell immunotherapy for the Treatment of Cancer. Front Immunol, 2015 Nov 17.

Ruggeri L, Capanni M, Urbani E, et al (2002). Effectiveness of donor natural killer cell alloreactivity in mismatched hematopoietic transplants. Science, 295, 2097-100.

Sun K, Alvarez M, Ames E, et al (2012). Mouse NK cell-mediated rejection of bone marrow allografts exhibits patterns consistent with Ly49 subset licensing. Blood, 119, 1590-8.

Tanaka J, Sugita J, Shiratori S, et al (2012). Expansion of NK cells from cord blood with antileukemic activity using GMP-compliant substances without feeder cells. Leukemia, 26, 1149-52.

Tarek N, Le Luduec J-B, Gallagher MM, et al (2012). Unlicensed NK cells target neuroblastoma following anti-GD2 antibody treatment. J Clin Invest, 122, 3260-70.

Valiante NM, Parham P (1997). Natural killer cells, HLA class I molecules, and marrow transplantation. Biol Blood Marrow Transplant J Am Soc Blood Marrow Transplant, 3, 229-35.

Welsh RM (1978). Cytotoxic cells induced during lymphocytic choriomeningitis virus infection of mice. I. Characterization of natural killer cell induction. J Exp Med, 148, 163-81.

\section{cc) (i) (8)}

This work is licensed under a Creative Commons AttributionNon Commercial 4.0 International License. 